\title{
Improvement of Traditional Village Protection Infrastructure Management System
}

\author{
Ji Chen ${ }^{l}$ Hongfu Zhang ${ }^{2}$ Yanan Cao* \\ ${ }^{1}$ College of Economic and Management, Yunnan Agricultural University, Kunming, Yunnan,650201, China \\ ${ }^{2}$ College of Mechanical and Electrical, Yunnan Agricultural University, Kunming, Yunnan,650201, China \\ *Corresponding author. Email: yanan.cao@foxmail.com
}

\begin{abstract}
At present, there are still problems in the traditional village infrastructure management system in China, such as improper investment, disordered construction and low resource utilization. While developing traditional villages, China should strengthen the protection of traditional villages through measures such as increasing investment in preliminary research, improving scientific management methods, establishing joint management committees, and improving the supervision system. Compared with ordinary villages, traditional villages have rich historical and cultural values and have a special historical status. They are a precious part of China's splendid civilization. The construction of infrastructure in traditional villages was originally set up to improve the living conditions of villagers. However, factors such as insufficient investment in infrastructure construction, disordered management, and low utilization rate have reduced the quality of life in traditional villages. On the other hand, they have restricted the speed and space of economic development. Therefore, it is of great significance to improve the traditional village infrastructure management system.
\end{abstract}

Keywords : traditional village protection, infrastructure, management system

\section{PROBLEMS IN INFRASTRUCTURE MANAGEMENT OF TRADITIONAL VILLAGES}

\subsection{Improper investment, not adapted to local conditions}

\subsubsection{Manufacturing safety hazards.}

Most of the traditional villages are surrounded by mountains and rivers, and the complexity of the mountainous terrain determines that there is a strong difference between traditional villages and even individual traditional villages, which is difficult to grasp completely accurately. Moreover, traditional villages have a long history. The terrain environment has changed in the past few centuries. The records and data left in the past cannot be fully applied.

Taking the construction of traffic roads as an example, transportation is an important part of infrastructure construction. However, the traditional villages are complex in terrain, the overall gap is large, the traditional streets and lanes are built for a long time, and the buildings on both sides are old and dangerous. Some terrains are not suitable for passing roads, but it is difficult to comprehensively adapt to local conditions during construction, and fully investigate the topographical features, thus laying a lot of safety hazards.
Communication and power facilities have become an indispensable infrastructure for villagers today. However, a large number of lines have not been integrated and planned during the introduction, the line interaction is complicated, and there are even a large number of private power lines. Most of the traditional village houses are kept as they are. The materials used are mainly stone and wood. When the fire occurs, the spread of the fire cannot be effectively prevented. Therefore, the introduction of the line has also left many safety hazards.

\subsubsection{Conflict with traditional village cultural beliefs}

The distinguishing feature of traditional villages from ordinary villages is that they have a rich history and culture. China is a multi-ethnic country. Not only is each nation different, but the same ethnic group is also distributed in different regions.

In the process of the formation of cultural beliefs, some of the belief rules advocated by the ancients can be explained by science today, but many concepts, especially the worship of nature, have been deeply rooted in the heart and continue to this day. So, In the process of infrastructure construction, it is difficult to completely grasp the cultural beliefs of each region, so it will cause conflicts with cultural beliefs to a certain extent. 


\subsection{Construction confusion, lack of perfect management system}

The construction of infrastructure includes transportation, agriculture, water conservancy, electric power and many other aspects. Different types of infrastructure have differences, and economic and environmental constraints have determined that many constructions cannot be completed at one time, and interval investment is required. Therefore, infrastructure construction lack of a holistic, long-term, and harmonious investment planning and management system.

In the process of construction, ancient villages paid great attention to the use of natural resources, especially water resources, and thus built traditional drainage and water systems. In modern times, new drainage systems have also been introduced into traditional villages. However, because traditional drainage facilities are built with the combination of previous geographical conditions and housing conditions, they cannot be fully utilized or completely removed, making it difficult to efficiently implement new systems in some areas.

The chaos of infrastructure has affected the overall layout of traditional villages on the surface, causing many inconveniences in life, and thus the living standards have declined and economic development has been restricted.

\subsection{Low infrastructure utilization}

Traditional villages have formed a series of intelligent production and life styles in farming and animal husbandry in the long history of development. The investment in modern infrastructure can improve production efficiency and promote the development of productivity to a certain extent. However, the continuation of centuries of tradition has made it difficult for villagers quickly adapt to new production methods and change them to the main mode of production. Therefore, the infrastructure cannot meet the needs and it is difficult to avoid the problem of idleness and low utilization.

\section{THE NECESSITY OF IMPROVE MANAGEMENT SYSTEMS}

According to the problems existing in the traditional village infrastructure management described above, there are many defects and shortcomings in the management mechanism from the preliminary investigation to the later management. Therefore, it is very important to improve the management system.

First, improving the traditional village infrastructure management system can reduce the contradiction between modernity and tradition. The speciality of traditional villages is performed from the inside to the outside. It is difficult to completely avoid the collision between tradition and modernity, both spatially and functionally. Therefore, a sound system can solve these contradictions to a certain extent and make the traditional villages face a positive and harmonious direction.

Second, efficient use of infrastructure can be achieved. The legacy of traditional infrastructure, the inadequacy of existing infrastructure, and the wrong input decisions have all contributed to the problem of low infrastructure utilization. To solve this problem, we must improve the management system and scientifically determine the most urgent needs of the moment. And under the supervision of the third party of the supervisory organization, work together to achieve the optimal use of resource allocation.

Finally, the harmonious development of traditional villages can be realized. For traditional villages, only the pursuit of economic development, the improvement of living standards is not the theme of its development, harmonious development is the primary goal of its development. Harmonious development first requires the protection of the material basis and historical culture of traditional villages, especially the protection of history and culture. Only by protecting our civilization can we continue our civilization and add a beautiful stroke to the books of Chinese civilization.

\section{SUGGESTIONS FOR A SOUND MANAGEMENT SYSTEM}

\subsection{Enhance the investment mechanism of the preliminary investigation and management}

Adapting to local conditions is an important guarantee and prerequisite for the efficient use and management of infrastructure. Due to its special historical culture and geographical environment, traditional villages are more important than development for protection. The destruction of traditional villages is the destruction of history and culture. Therefore, the investment in the previous survey must be intensified and comprehensively evaluated from the aspects of historical culture and geographical conditions.

The villagers in the traditional villages are the fundamental source and driving force for the village to inherit and develop. Therefore, it is necessary to visit the local traditional residents, find out from their complaints, use scientific methods to analyze the survey data, clarify the current actual needs, and look at all aspects of traditional villages be a whole. scientifically Improve the preliminary inspection system.

\subsection{Improve scientific management methods}

The particularity of traditional villages determines that it is impossible to copy the successful management model of ordinary villages, nor to stubbornly maintain the existing model without change, but to improve scientific management methods according to characteristics and changes. 
Fundamentally, we must grasp the principle of overall unity and partial adjustment. The same village divides different areas according to the characteristics of previous investigations. For example, in an open and flat area, attention can be paid to improving traffic roads and parking areas, because motor vehicles now almost completely replace traditional vehicles, the number of users is increasing, the traditional village roads are narrow, and the houses are too dense enough to meet the driving and parking needs.

The combination of tradition and modernity can not only focus on the introduction of modern infrastructure, but also combine the scientific reuse of traditional infrastructure or scientific integration with modern infrastructure to reduce input costs and improve the adaptability of infrastructure and traditional villages.

\subsection{Setting up the co-management committee}

The Co-management Committee is a specialized agency for coordinating the work of the government and the will of the people. On the one hand, the needs of the people can be met, and at the same time, the government's work can be smoothly carried out. The main body of the co-management committee is the community, government and social forces, and the stakeholders are included. The personnel who contributed to the rationalization and scientific construction. At the same time as setting up the co-management committee, it is necessary to establish and improve the rules and regulations, and retain the initiative of the members of the committee as much as possible, so that the members of the committee actively participate in the construction and maintenance of the village infrastructure. However, due to the large number of administrative departments in village infrastructure management, in order to coordinate the work of various parts, the author believes that the daily management of the various departments of the co-management committee can be implemented. In the construction and maintenance of infrastructure, the co-management committee is responsible for coordinating work. On the basis of the impact of management efficiency, each part establishes a bridge of communication, which enables each department to help each other and improve management efficiency, thus effectively avoiding problems such as unreasonable supply and inadequate supervision.

\subsection{Establish supervision institutions and improve supervision system}

Improving the scientific management method does not represent the success of infrastructure management. Only serious implementation is the key to success. Management methods also need to be implemented in a timely manner, because the constant changes of the times will make a certain set of "scientific" management methods no longer "scientific", and will inevitably increase the time and energy costs of input. Therefore, it is necessary to establish a supervision organization for infrastructure management, thus supervising the implementation of relevant policy methods. The so-called scientific management method can only test whether it is scientific in practice, and the breadth and intensity of supervision should be sufficient.

\section{ACKNOWLEDGEMENT}

This research was financially supported by Yunnan Agricultural University Social Science Program for Youth and Middle-age researchers (2016SK21).

\section{REFERENCES}

[1] Lin Zurui, Ma Tao, Chang Jiang, Yu Yang. Research on Evaluation of Coordinated Development of Traditional Village Infrastructure. Industrial Construction, 2015, 45(10): 53-60

[2] Zhang Pengfei, Li Tao. Research on the Co-management Mechanism of Traditional Village Infrastructure [A]. Rural Science and Technology Sannong Forum, 2017, 06 (002): 12-14

[3] Wang Wei. Research on infrastructure improvement measures for historical and cultural villages [TU]. South China University of Technology, 2012

[4] Ji Chen. Investigation and Analysis of Villagers Participation in Protection of Traditional Villages_Case study in Shaxi [C]. Science and Engineering Research Center. Proceedings of 2018 3rd International Conference on Education, Management and Systems Engineering (EMSE 2018). Science and Engineering Research Center: Science and Engineering Research Center,2018:241-244.

[5] Suhani. Legal Protection of Village Land for Infrastructure Development in Indonesia. Proceedings of the 2nd International Conference on Indonesian Legal Studies (ICILS 2019), 2019.

[6] Xiao Li. Research on the Infrastructure of Traditional Villages. South China University of Technology,2016. 